\title{
EIF1AX c.338-2A $>$ T splice site mutation in a patient with trabecular adenoma and cytological indeterminate lesion
}

\author{
Maria Grazia Castagna \\ https://orcid. org/0000-0002-2457-1751 \\ Tania Pilli ${ }^{1}$ \\ https://orcid.org/0000-0002-1171-6384 \\ Fabio Maino' \\ https://orcid.org/0000-0002-4417-2264 \\ Carlotta Marzocchi ${ }^{1}$ \\ https://orcid. org/0000-0002-8573-4913 \\ Giovanni Di Cairano' \\ https://orcid. org/0000-0002-3290-9732 \\ Silvia Cantara ${ }^{1}$ \\ https://orcid.org/0000-0002-5741-295X
}

\section{SUMMARY}

The EIF1AX gene mutations have been recently associated with papillary thyroid carcinoma and anaplastic thyroid cancer. According with these reports, the gene as been considered as a drive gene for thyroid cancer development. However, the occurrence of these alterations in benign thyroid lesions is not known and is still under investigation. Some authors have already reported the presence of EIF1AX variants in follicular adenomas and hyperplastic nodules. Here, we describe for the first time a case of a man with the EIF1AX c.338-2A>T splice site mutation in an indeterminate FNA lesion with trabecular adenoma at final histology in the absence of other pathogenetic mutations, demonstrating that further studies are required to better understand EIF1AX role in the tumorigenesis of thyroid carcinoma. Arch Endocrinol Metab. 2020;64(2):185-9

\author{
Correspondence to: \\ Silvia Cantara \\ Department of Medical, \\ Surgical and Neurological Sciences, \\ University of Siena, Siena, Italy \\ Viale Bracci 16 \\ 53100 - Siena, Italy \\ cantara@unisi.it \\ Received on May/5/2019 \\ Accepted on Sept/16/2019
}

DOI: $10.20945 / 2359-3997000000208$

\section{INTRODUCTION}

A round $15-30 \%$ of all thyroid lesions investigated by fine needle aspiration cytology (FNAC) are of indeterminate origin. Among these, 5-15\% are atypia of undetermined significance/follicular lesion of undetermined significance (AUS/FLUS) and 20-30\% are follicular neoplasm/suspicious for follicular neoplasm (FN) (Bethesda Classification System) (1). The overall risk of cancer is $34-42 \% \%$ ( 1 ) and thus to apply surgery to all indeterminate lesions will end in approximately $60-70 \%$ of unnecessary operations. The identification of genetic alterations specific for differentiated thyroid cancer have supplied molecular markers to be searched for in the material obtained by fine needle aspiration (FNA), thus enhancing the diagnostic accuracy of traditional cytology. The European Thyroid Association (ETA) recently published a document (2) about clinical recommendations on the use of molecular diagnostics in the evaluation of indeterminate cytologies. In particular, ETA guidelines recommend the search of at least BRAF, RAS point mutations (N-, H-, and K-RAS) and RET/PTCl-3, PAX8/PPARG rearrangements (7 gene panel). This panel has been shown in several reports to have a good sensitivity and specificity with a negative predictive value of $56-100 \%(2-7)$. With the increased of molecular techniques and the advent of next generation sequencing a larger mutation panel was proposed for the molecular diagnosis of indeterminate lesions (8-15). The Thyroseq platform has been shown a sensitivity of $74-91 \%$, specificity $50-92 \%$ and a NPV of $89-97 \%(10,11,13,14,16-24)$. In addition to the 7 gene panel, Thyroseq suggest the search of several variants such as ALK, NTRK3 gene fusions and mutations of hTERT, EIFlAX that considered together account for $12 \%$ of all thyroid cancers. 


\section{CASE REPORT}

A 55 year old man was referred to our clinic of Endocrinology, University-Hospital of Siena because of the presence of multinodular goiter. Blood samples showed normal levels of thyroperoxidase (AbTPO) and thyroglobulin antibodies. The patient was euthyroid with $0.5 \mu \mathrm{U} / \mathrm{ml}$ of thyroid-stimulating hormone (TSH) (range $0.4-4.0 \mu \mathrm{U} / \mathrm{ml}$ ), $3.6 \mathrm{pg} / \mathrm{ml}$ of free triiodothyronine (FT3) (range $2.5-4.5 \mathrm{pg} / \mathrm{mL}$ ), and $7.8 \mathrm{pg} / \mathrm{mL}$ of free thyroxine (FT4) (range 5.8-16.40 $\mathrm{pg} / \mathrm{mL}$ ). At physical examination, a palpable nodule of $\sim 1.5 \mathrm{~cm}$ in size was detected in the left lobe of the thyroid gland. The neck ultrasound confirmed the presence of a dominant thyroid nodule with sonographic features of solid hypoechoic, lobulated margins, taller than wider $(2.0 x 1.6 x 1.7 \mathrm{~cm})$ and intranodular vascularity. Therefore, a FNAC was performed under ultrasound guidance and cytological results revealed a AUS/FLUS lesion. According with ETA guidelines, the genetic analysis was applied to the lesion in order to refine pre-operative diagnosis. We first verified thyroid origin of the FNA material by analyzing TPO and TSHR expression. Then, the FNA specimen was sequenced for the seven gene panel. In addition, EIFlAX (exons 2, 5 and 6), ALK fusions, hTERT and p53 (exons 5 and 7) point mutations were analyzed. The FNA sample was negative for all (Table 1), but was found to carry a c.338-2A>T splice site mutation (Figure $1 \mathrm{~A}$ ) in the eukaryotic translation initiation factor $\mathrm{lA}, \mathrm{X}$-linked (EIFlAX) which abolish the splice acceptor site of exon 6 resulting in two alternative spliced mRNA (25). Given the association of EIFIAX as a driver gene in papillary thyroid carcinoma (PTC) and the presence is some cases of anaplastic thyroid cancer (ATC) (26), the patient was recommended to undergo thyroid surgery. The final pathologic diagnosis was trabecular adenoma

Table 1. Panel analyzed and results of sequencing for our patient

\begin{tabular}{lc}
\hline Oncogene analyzed & Results for mutation \\
\hline BRAF V600E & Negative \\
BRAF K601E & Negative \\
RET/PTC1 and RET/PTC3 & Negative \\
PAX8/PPAR $\gamma$ & Negative \\
hTERT (C228T, C250T) & Negative \\
ALK fusions & Negative \\
H-N-K RAS (condons 12 and 61) & Negative \\
TP53 (exons 5 and 7) & Negative \\
EIF1AX (exons 2, 5 and 6) & C.338-2A>T splice site \\
\hline
\end{tabular}

(a benign lesion characterized by cells which are closely packed to form cords with only a few small follicles) with presence of Hürthle cells. Genomic analysis of the surgical specimen confirmed the presence of the a c.338-2A $>\mathrm{T}$ nucleotide change in EIFIAX in the absence of the other mutations (BRAF, N-, H-, and K-RAS, RET/PTCl-3, PAX8/PPARG, ALK, hTERT and $\mathrm{p} 53$ ).

\section{Comment}

The Eukaryotic Translation Initiation Factor 1A, $\mathrm{X}$-Linked (EIFIAX) gene encodes a crucial eukaryotic translation initiation factor. The protein is required for the binding of the $43 \mathrm{~S}$ complex (a $40 \mathrm{~S}$ subunit, eIF2/ GTP/Met-tRNAi and eIF3) to the 5' end of capped RNA (GeneCard). Furthermore, over-expression of ElFlAX increases expression of Cyclin Dl inducing cell proliferation. Recently, variations in this gene have been associated with thyroid cancer both papillary and anaplastic (26). Mostly, these reports have identified the c.338-1G>T splice site mutation in combination with RAS mutations (mainly NRAS p.Q61K and p.Q61R) (27-28). Our patient was negative for RAS mutations (figure $\mathrm{IB}, \mathrm{C}$ and $\mathrm{D}$ ). The prevalence of EIFIAX in benign lesions is still under investigation. In 2016, Karunamurthy and cols. (27) found the Al13_splice mutation in $7.4 \%$ of follicular adenomas and $1.3 \%$ of hyperplastic nodules in a series of 266 sample. Given the fact that the alteration was present also in $2.3 \%$ of PTC and $25 \%$ of ATC, they concluded that when found in thyroid FNA, EIFIAX confers approximately $20 \%$ risk of cancer. In the same year, Yoo and coworkers published a comprehensive analysis of the trascriptome and genome of follicular versus papillary thyroid cancer (29). They compared the RNA sequencing results of 77 PTCs, 48 follicular variant of PTC (FVPTC), 30 minimally invasive follicular thryoid cancer (miFTC) and 25 follicular adenomas (FA) to understand the differences in their molecular properties. EIFIAX was found only in $5.45 \%$ of the sample of miFTC or FA origin without the coexistence of BRAF or RAS mutations (29). Recently the c.338-1G>T was found for the first time in a case of Hurtle cell carcinoma (30). This patient carried no mutation in RAS genes but was found to have a mutation in the TP53 possibly responsible for the more aggressive behavior of the tumor (30). At contrast with this study, our patient was also negative for TP53 mutations (Table 1). Same group reported a rare case of a follicular adenoma harboring the C228T mutation in TERT 
gene, the Q61R mutation in HRAS, and the c.338IG>T splice mutation in EIFlAX gene (31). In another study (32) in which 201 follicular-patterned thyroid tumors were analyzed, the authors found EIFIAX only in one case of adenoma concluding that, EIFIAX has limited impact on molecular diagnostics of thyroid tumors. Opposite conclusions are given by Jung and coworkers which state that EIFlAX together with EZHl, TSHR, and BRAF mutations may play roles in the initial development and progression of follicular tumors (33). A possible limitation of our study, could be the absence a scintigraphy to exclude the presence of a pre-toxic

A

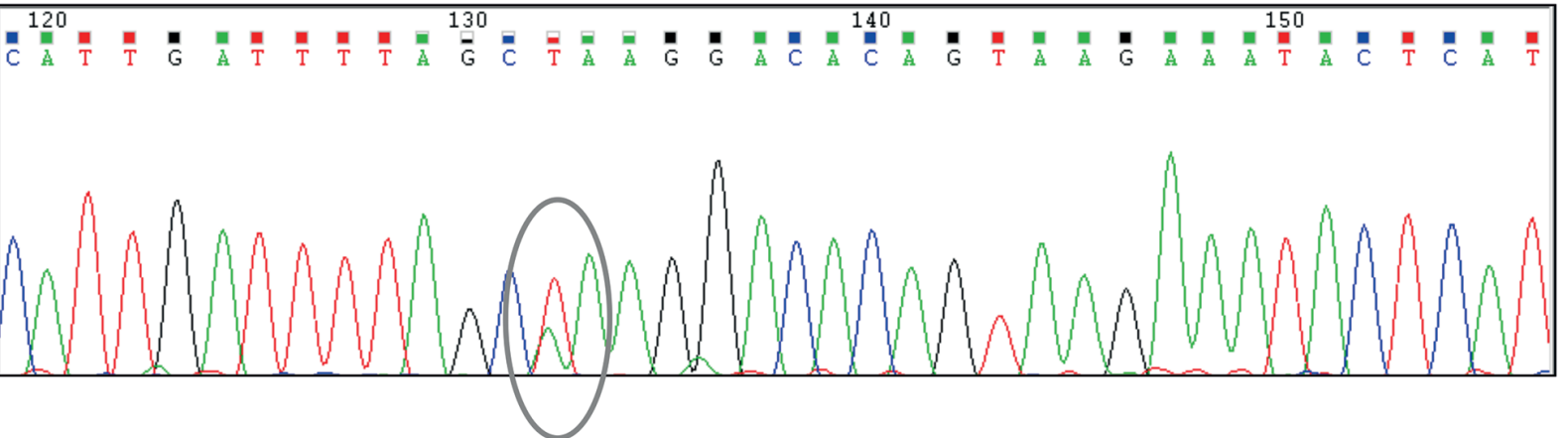

B

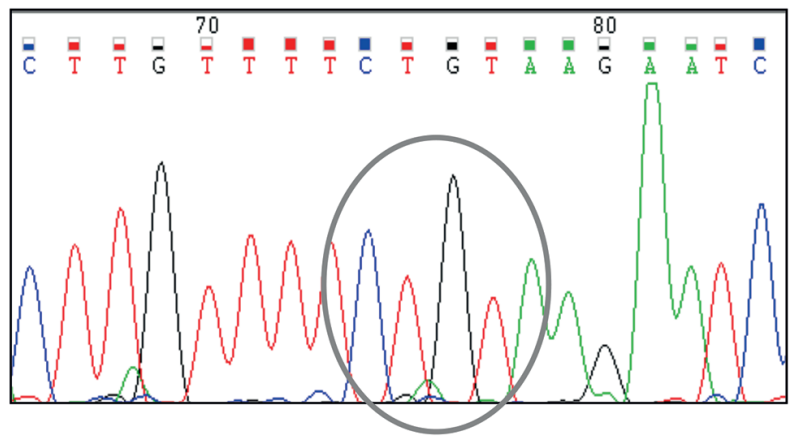

C
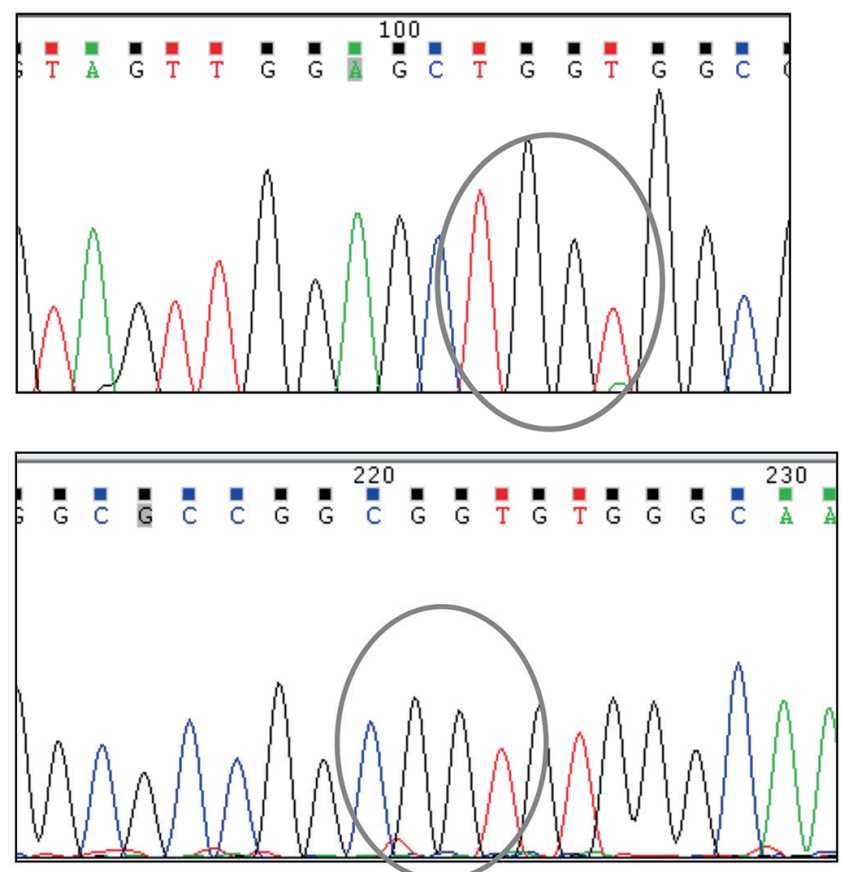
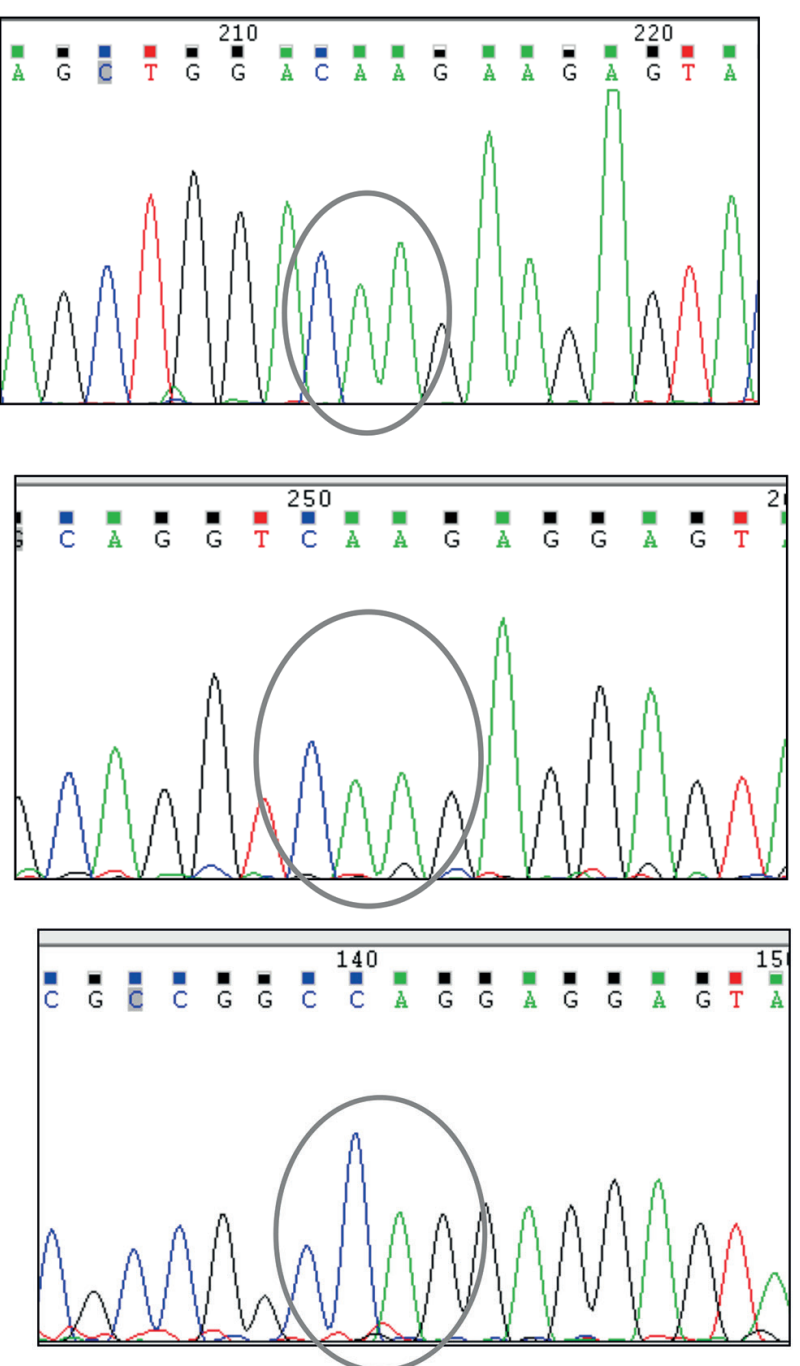

Figure 1. (A) Electropherogram for EIF1AX exon 6. The splice site region is evidenced in the circle. (B) Sequences for NRAS codon 12 (left) and codon 61 (right). (C) Sequences for KRAS codon 12 (left) and codon 61 (right). D: Sequences for HRAS codon 12 (left) and codon 61 (right). For all, in the circle is evidences the hot spot site. 
nodule. The exam was suggested to the patient, who refused it, preferring to undergo surgical treatment. Moreover, in pre-toxic nodule, TSHR mutations can be found even associated with EIFIAX mutations (33). Unfortunately, TSHR mutations were not evaluated in the present study, due to low material obtained from FNA (RNA: $12.4 \mathrm{ng} / \mathrm{ul}$; DNA: $6.1 \mathrm{ng} / \mathrm{ul}$ ) and from the post-surgical tissue specimen (RNA: $8 \mathrm{ng} / \mathrm{ul}$ and DNA: $4.3 \mathrm{ng} / \mathrm{ul})$.

In conclusion, we describe for the first time the presence of EIFIAX c.338-2A $>$ T splice site mutation in a trabecular adenoma with the absence of other known pathogenetic mutations and again we open the question whether EIFIAX splice region variants may represent an early genetic event in the molecular pathogenesis of follicular thyroid carcinoma or can be present in exclusively benign lesions without consequence on cell transformation. In this case, the aggressive phenotype described in other reports $(27,28,30)$ can be associated only with the presence of RAS or TP53 variants.

All procedures followed were in accordance with the ethical standards of the responsible committee on human experimentation (institutional and national) and with the Helsinki Declaration of 1975 , as revised in 2000. Informed consent was obtained from all patients for being included in the study.

Disclosure: no potential conflict of interest relevant to this article was reported.

\section{REFERENCES}

1. Bongiovanni M, Spitale A, Faquin WC, Mazzucchelli L, Baloch ZW. The Bethesda System for Reporting Thyroid Cytopathology: a meta-analysis. Acta Cytol. 2012;56:333-9.

2. Paschke R, Cantara S, Crescenzi A, Jarzab B, MusholtTJ, Sobrinho Simoes M. European Thyroid Association Guidelines regarding Thyroid Nodule Molecular Fine-Needle Aspiration Cytology Diagnostics. EurThyroid J. 2017;6(3):115-29.

3. Nikiforov YE, Ohori NP, Hodak SP, Carty SE, LeBeau SO, Ferris $\mathrm{RL}$, et al. Impact of mutational testing on the diagnosis and management of patients with cytologically indeterminate thyroid nodules: a prospective analysis of 1056 FNA samples. J Clin Endocrinol Metab. 2011;96:3390-7.

4. Labourier E, Shifrin A, Busseniers AE, Lupo MA, Manganelli ML, Andruss $B$, Wylie D, et al. Molecular Testing for miRNA, mRNA, and DNA on Fine-Needle Aspiration Improves the Preoperative Diagnosis ofThyroid Nodules with Indeterminate Cytology. J Clin Endocrinol Metab. 2015;100:2743-50.

5. Eszlinger M, Piana S, Moll A, Bösenberg E, Bisagni A, Ciarrocchi $A$, et al. Molecular testing of thyroid fine-needle aspirations improves presurgical diagnosis and supports the histologic identification of minimally invasive follicular thyroid carcinomas. Thyroid. 2015;25:401-9.

6. Cantara S, Capezzone M, Marchisotta S, Capuano S, Busonero $G$, Toti $P$, et al. Impact of proto-oncogene mutation detection in cytological specimens from thyroid nodules improves the diagnostic accuracy of cytology. J Clin Endocrinol Metab. 2010;95:1365-9.
7. Beaudenon-Huibregtse S, Alexander EK, Guttler RB, Hershman JM, Babu V, Blevins TC, et al. Centralized molecular testing for oncogenic gene mutations complements the local cytopathologic diagnosis of thyroid nodules. Thyroid. 2014;24:1479-87.

8. Nikiforova MN, Wald Al, Roy S, Durso MB, Nikiforov YE. Targeted next-generation sequencing panel (ThyroSeq) for detection of mutations in thyroid cancer. J Clin Endocrinol Metab. 2013;98:E1852-60.

9. Nikiforov YE, Carty SE, Chiosea SI, Coyne C, Duvvuri U, Ferris RL, et al. Highly accurate diagnosis of cancer in thyroid nodules with follicular neoplasm/suspicious for a follicular neoplasm cytology by ThyroSeq v2 next-generation sequencing assay. Cancer. 2014; 120:3627-34.

10. Nikiforov YE, Carty SE, Chiosea SI, Coyne C, Duvvuri U, Ferris $\mathrm{RL}$, et al. Impact of the Multi-Gene ThyroSeq Next-Generation Sequencing Assay on Cancer Diagnosis in Thyroid Nodules with Atypia of Undetermined Significance/Follicular Lesion of Undetermined Significance Cytology. Thyroid. 2015;25:1217-23.

11. Nikiforova MN, Mercurio S, Wald Al, Barbi de Moura M, Callenberg K, Santana-Santos L, et al. Analytical performance of the ThyroSeq v3 genomic classifier for cancer diagnosis in thyroid nodules. Cancer. 2018;124:1682-90.

12. Pearlstein S, Lahouti AH, Opher E, Nikiforov YE, Kuriloff DB. Thyroseq V3 Molecular Profiling for Tailoring the Surgical Management of Hürthle Cell Neoplasms. Case Rep Endocrinol. 2018;2018:9329035.

13. Steward DL, Carty SE, Sippel RS, Yang SP, Sosa JA, Sipos JA, et al. Performance of a Multigene Genomic Classifier in Thyroid Nodules with Indeterminate Cytology: A Prospective Blinded Multicenter Study. JAMA Oncol. 2019;5:204-212.

14. Nikiforov YE, Baloch ZW. Clinical validation of the ThyroSeq v3 genomic classifier in thyroid nodules with indeterminate FNA cytology. Cancer Cytopathol. 2019;127:225-30.

15. Ohori NP, Landau MS, Carty SE, Yip L, LeBeau SO, Manroa P, et al. Benign call rate and molecular test result distribution ofThyroSeq v3. Cancer Cytopathol. 2019;127:161-8.

16. Mayson SE, Haugen BR. Molecular Diagnostic Evaluation of Thyroid Nodules. Endocrinol Metab Clin North Am. 2019;48:85-97.

17. Borowczyk M, Szczepanek-Parulska E, Olejarz M, Wiçckowska B, Verburg FA, Dçbicki S, et al. Evaluation of 167 Gene Expression Classifier (GEC) and ThyroSeq v2 Diagnostic Accuracy in the Preoperative Assessment of Indeterminate Thyroid Nodules: Bivariate/HROC Meta-analysis. Endocr Pathol. 2019;30:8-15.

18. Marcadis AR, Valderrabano P, Ho AS, Tepe J, Swartzwelder CE, Byrd S, et al. Interinstitutional variation in predictive value of the ThyroSeq v2 genomic classifier for cytologically indeterminate thyroid nodules. Surgery. 2019;165:17-24.

19. Pearlstein S, Lahouti AH, Opher E, Nikiforov YE, Kuriloff DB. Thyroseq V3 Molecular Profiling for Tailoring the Surgical Management of Hürthle Cell Neoplasms. Case Rep Endocrinol. 2018;2018:9329035.

20. Rivas AM, Nassar A, Zhang J, Casler JD, Chindris AM, Smallridge $\mathrm{R}$, et al. ThyroSeq ${ }^{\circledR V} 2.0$ Molecular Testing: A Cost-Effective Approach for the Evaluation of Indeterminate Thyroid Nodules. Endocr Pract. 2018;24:780-8.

21. Jug RC, Datto MB, Jiang XS. Molecular testing for indeterminate thyroid nodules: Performance of the Afirma gene expression classifier andThyroSeq panel. Cancer Cytopathol. 2018;126:471-80.

22. Livhits MJ, Kuo EJ, Leung AM, Rao J, Levin M, Douek ML, et al. Gene Expression Classifier vs Targeted Next-Generation Sequencing in the Management of Indeterminate Thyroid Nodules. J Clin Endocrinol Metab. 2018;103:2261-8.

23. Taye A, Gurciullo D, Miles BA, Gupta A, Owen RP, Inabnet WB 3rd, et al. Clinical performance of a next-generation sequencing assay (ThyroSeq v2) in the evaluation of indeterminate thyroid nodules. Surgery. 2018;163:97-103. 
24. Valderrabano P, Khazai L, Leon ME, Thompson ZJ, Ma Z, Chung $\mathrm{CH}$, et al. Evaluation of ThyroSeq v2 performance in thyroid nodules with indeterminate cytology. Endocr Relat Cancer. 2017;24:127-36.

25. Krishnamoorthy GP, Davidson NR, Leach SD, Zhao Z, Lowe SW, Lee G, et al. EIF1AX and RAS Mutations Cooperate to Drive Thyroid Tumorigenesis through ATF4 and c-MYC. Cancer Discov. 2019;9:264-81.

26. Cancer Genome Atlas Research N. Integrated genomic characterization of papillary thyroid carcinoma. Cell. 2014;159:676-90.

27. Karunamurthy A, Panebianco F, J Hsiao S, Vorhauer J, Nikiforova MN, Chiosea S, Nikiforov YE. Prevalence and phenotypic characteristics of EIF1AX mutations in thyroid nodules. Endocrine-related cancer. 2016;23:295-301.

28. Landa I, IbrahimpasicT, Boucai L, Sinha R, Knauf JA, Shah RH, et al. Genomic and transcriptomic hallmarks of poorly differentiated and anaplastic thyroid cancers. J Clin Invest. 2016;126:1052-66.
29. Yoo SK, Lee S, Kim SJ, Jee HG, Kim BA, Cho H, et al. Comprehensive Analysis of the Transcriptional and Mutational Landscape of Follicular and Papillary Thyroid Cancers. PLoS Genet. 2016;12:e1006239.

30. Topf MC, Wang ZX, Furlong K, Miller JL, Tuluc M, Pribitkin EA. EIF1AX Mutation in a Patient with Hürthle Cell Carcinoma. Endocr Pathol. 2018;29:27-9.

31. Topf MC, Wang ZX, Tuluc M, Pribitkin EA. TERT, HRAS, and EIF1AX Mutations in a Patient with Follicular Adenoma. Thyroid. 2018;28:815-7.

32. Jung CK, KimY, Jeon S, Jo K, Lee S, Bae S. Clinical utility of EZH1 mutations in the diagnosis of follicular-patterned thyroid tumors. Human Pathology. 2018;81:9-17.

33. Jung SH, Kim MS, Jung CK, Park HC, Kim SY, Liu J, et al. Mutational burdens and evolutionary ages of thyroid follicular adenoma are comparable to those of follicular carcinoma. Oncotarget. 2016;7:69638-48. 